\title{
Correlation of lateral placental location with development of preeclampsia
}

\author{
Anjali Gupta, Priyanka Bansal*, Jyotsna Sen, Savita Rani Singhal
}

Department of Obstetrics and Gynecology, Pt. B.D. Sharma PGIMS, Rohtak, Haryana, India

Received: 13 November 2019

Revised: 27 January 2020

Accepted: 01 February 2020

\author{
*Correspondence: \\ Dr. Priyanka Bansal, \\ E-mail: pribns126nov@gmail.com
}

Copyright: ( $)$ the author(s), publisher and licensee Medip Academy. This is an open-access article distributed under the terms of the Creative Commons Attribution Non-Commercial License, which permits unrestricted non-commercial use, distribution, and reproduction in any medium, provided the original work is properly cited.

\begin{abstract}
Background: Preeclampsia is a complex clinical syndrome which involves multiple organ systems and remains the principle cause of maternal and perinatal morbidity and mortality. Preeclampsia is a disease of trophoblastic tissue. Placental abnormality is one of the initial events in patients who are destined to develop pregnancy induced hypertension subsequently. Objective of this study was to evaluate the association of laterally located placenta on ultrasound with development of preeclampsia.

Methods: This prospective observational study was conducted on 200 antenatal women with singleton pregnancy at 18-24 weeks of gestation who attended antenatal clinic of obstetrics and gynaecology, PGIMS Rohtak from October 2017 to October 2018. Detailed antenatal transabdominal ultrasound along with placental location was done between 18-24 weeks of gestation in women who fitted into inclusion criteria. All the antenatal women belonged to 18-24 weeks of gestation were included in the study except those women with chronic hypertension, diabetes mellitus, renal disease, severe anaemia, thyrotoxicosis, low lying placenta, previous history of preeclampsia or eclampsia.

Results: Out of 200 antenatal women, 84 had lateral placenta while 116 had central placenta. Out of these 84 women who had lateral placenta, 55 women $(65.5 \%)$ developed preeclampsia and out of $116(58 \%)$ women who had central placenta, 28 women $(24.1 \%)$ developed preeclampsia.

Conclusions: From the above study, we concluded that women with laterally located placenta by ultrasound at 18-24 weeks of gestation have greater risk of developing preeclampsia.
\end{abstract}

Keywords: Central placenta, Lateral placenta, Placenta, Preeclampsia, Ultrasonography

\section{INTRODUCTION}

Preeclampsia is a multisystem disorder and is defined as hypertension developing after 20 weeks gestation with one or more of the following: proteinuria, maternal organ dysfunction (including renal, hepatic, hematological or neurological complications), or fetal growth restriction. ${ }^{1}$ It complicates $5-7 \%$ of first pregnancies and $2-10 \%$ of all pregnancies. $^{2}$ The exact pathogenesis of preeclampsia still remains the subject of research, but it is believed that it is likely to be multifactorial. The factors currently considered to be most important are maternal immunological intolerance, abnormal placental implantation, genetics, nutritional, environmental, cardiovascular. Pregnancy results in profound anatomical, physiological, hematological, metabolic and inflammatory changes in maternal tissues. ${ }^{3}$

Preeclampsia is a disease of trophoblastic tissue. ${ }^{4}$ Placental abnormality is one of the initial events in patients who are destined to develop pregnancy induced hypertension subsequently. ${ }^{5}$ 
Preeclampsia is thought to be a major cause of maternal and perinatal morbidity and mortality. The majority of deaths related to preeclampsia can be prevented by providing timely and effective care to pregnant women presenting with such complications. ${ }^{6}$ Worldwide about 76,000 pregnant women die each year from preeclampsia and its related complications. ${ }^{7}$

Infants of women with severe pregnancy induced hypertension have five-fold increase in mortality compared to infants of normotensive woman. ${ }^{8}$ This has led to the interest in screening and preventing this disorder but the most important factor is lack of timely prediction.

Numerous clinical, biochemical and biophysical tests in early or mid-pregnancy have been proposed for prediction of preeclampsia. These predictive tests are related to placental perfusion and vascular resistance (mean second trimester BP, cold pressor test, isometric hand grip exercise, roll over test, intravenous infusion of angiotensin II, 24 hour ambulatory BP monitoring), fetoplacental unit endocrinology (alpha- fetoprotein, human chorionic gonadotropin), renal function (serum uric acid or microalbuminuria), endothelial function (antiphospholipid antibodies, or homocysteine) and circulating angiogenic factors. ${ }^{9}$ Most tests in this category are cumbersome, time consuming and overall inaccurate.

Among the various predictors for preeclampsia, the placental location by ultrasound at 18-24 weeks is very cost effective, non-invasive and has a good predictive value. ${ }^{10}$ Kannamani and Narasimhan showed that placental position as determined by ultrasound between 18-20 weeks of gestation is an excellent screening test with a very high sensitivity. ${ }^{11}$ The present study was done to know if there is any correlation in lateral placental location with preeclampsia; and maternal and fetal outcome.

\section{METHODS}

This prospective observational study was conducted on 200 antenatal women with singleton pregnancy at 18-24 weeks of gestation attending antenatal clinic of obstetrics and gynaecology department at tertiary hospital in collaboration with Radiodiagnosis department.

\section{Exclusion criteria}

Women with chronic hypertension, diabetes mellitus, renal disease, severe anaemia, thyrotoxicosis, low-lying placenta, previous history of preeclampsia or eclampsia were excluded from the study.

The sample size taken was 200 after calculation and taking 5\% absolute error.

All the subjects recruited in the study were subjected to detailed history, general physical examination, systemic and obstetric examination at the time of antenatal visits and at admission. All routine antenatal investigations and specific investigations like platelet count, liver function test, renal function test, fundus examination and 24-hour urine for volume, protein and creatinine were carried out in women who had developed preeclampsia. Detailed antenatal transabdominal ultrasound along with placental location was done between 18-24 weeks of gestation. Women were divided into 2 groups depending on placental location.

- Group A: Women with lateral placental location.

- Group B: Women with central placental location.

The placenta was classified as central when it is equally distributed between right and left side of uterus irrespective of anterior, posterior or fundal position. When $>75 \%$ of placental mass is on one side of midline, it was classified as lateral placenta.

All the subjects were followed till delivery and were assessed for development of pre-eclampsia, and maternal and fetal outcome was noted.

\section{Statistical analysis}

At the end of the study, data was compiled and analyzed by using Chi-square test. Data analysis was done using statistical package for the social sciences 20 (SPSS 20), and a $\mathrm{p}$ value of $<0.05$ was considered significant.

\section{RESULTS}

Among total 200 women, age of the study population ranges from 17-36 years with mean age 24.22 \pm 3.17 and the maximum number of women were in the age group of 21-25 years. Table 1 shows the distribution of women according to placental location. Table 2 shows the demographic profile of study women according to placental location. Majority of women in both the groups were nulliparous.

\section{Table 1: Distribution of women according to placental location.}

\begin{tabular}{|lll|}
\hline Placenta location & Frequency $(\mathbf{n = 2 0 0 )}$ & $\%$ \\
\hline Group A (lateral) & 84 & $42 \%$ \\
\hline Group B (central) & 116 & $58 \%$ \\
\hline
\end{tabular}

The association of placental location with development of preeclampsia is depicted in Figure 1. Out of total women, $65.5 \%$ with lateral placenta and $34.5 \%$ with central placenta developed preeclampsia. This difference was found to be highly significant statistically ( $p$ value $<0.001$ ). Overall risk of developing preeclampsia with laterally located placenta was 5.96 (odds ratio) at $95 \%$ confidence interval (3.210 to 11.069). Table 3 shows distribution of women according to severity of preeclampsia. Severe preeclampsia developed in $22.62 \%$ 
women with lateral placenta and $2.59 \%$ women with central placenta. This difference was found to be statistically significant ( $\mathrm{p}$ value 0.05 ). So, the overall risk of developing severe preeclampsia with lateral placenta was 4.398 (odds ratio) at 95\% confidence interval (1.17416.46).

Table 2: Demographic profile of study population.

\begin{tabular}{|c|c|c|c|}
\hline & \multicolumn{2}{|c|}{ Placental location } & \multirow[b]{2}{*}{$\begin{array}{l}\text { Statistical } \\
\text { significance } \\
\text { (p value) }\end{array}$} \\
\hline & $\begin{array}{l}\text { Lateral } \\
(\text { Group A) } \\
(\mathbf{n}=\mathbf{8 4})\end{array}$ & $\begin{array}{l}\text { Central } \\
(\text { Group B) } \\
(\mathbf{n}=116)\end{array}$ & \\
\hline $\begin{array}{l}\text { Mean } \\
\text { age } \pm \text { SD }\end{array}$ & $23.75 \pm 3.04$ & $24.56 \pm 3.24$ & \\
\hline \multicolumn{4}{|l|}{ Parity } \\
\hline P0 & $54(64.3 \%)$ & $67(57.8 \%)$ & \multirow{5}{*}{$\begin{array}{l}0.530 \text { (not } \\
\text { significant) }\end{array}$} \\
\hline $\mathrm{P} 1$ & $18(21.4 \%)$ & $25(21.6 \%)$ & \\
\hline $\mathrm{P} 2$ & $7(8.3 \%)$ & $18(15.5 \%)$ & \\
\hline P3 & $3(3.6 \%)$ & $5(4.3 \%)$ & \\
\hline$\geq \mathrm{P} 4$ & $2(2.4 \%)$ & $1(0.9 \%)$ & \\
\hline
\end{tabular}

Women with preeclampsia presented with epigastric pain, blurring of vision, vomiting, headache and pedal edema. Though all the symptoms were found to be higher in women with lateral placenta, but there was no statistically significant difference except headache which was found to be statistically significant ( $p$ value 0.002 ). Most of the women with lateral placenta had urine albumin $>2+$ (i.e.
$>1 \mathrm{~g} / \mathrm{dl}$ ) while most of the women with central placenta had urine albumin $<1+($ i.e. $<0.30 \mathrm{~g} / \mathrm{dl}$ ). This difference was found to be statistically significant ( $\mathrm{p}$ value $<0.05$ ).

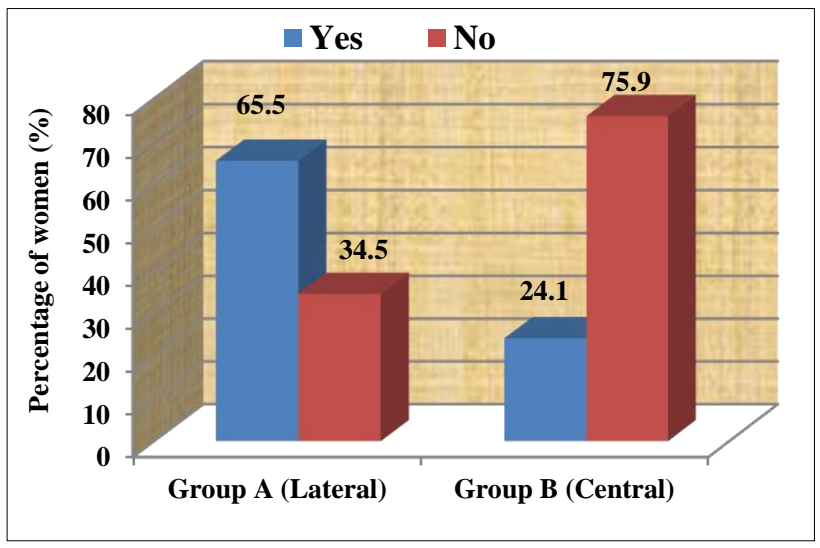

Figure 1: Pre-eclampsia development with placental location.

Maximum number of women i.e. $52.7 \%$ with lateral placenta developed preeclampsia at 31-36 weeks of gestation while maximum women with central placenta i.e. $67.9 \%$ developed preeclampsia at or after 36 weeks of gestation and was found to be statistically significant ( $\mathrm{p}$ value 0.025$)$. In both the groups, maximum women (82.1\% women in Group A and $88.8 \%$ women in Group B) delivered at or after 36 weeks of gestation.

Table 3: Severity of preeclampsia with placental location.

\begin{tabular}{|llll|}
\hline \multirow{2}{*}{ Preeclampsia } & Placental location & & Statistical significance (p value) \\
\cline { 1 - 3 } Mild & Lateral $($ Group A) $(\mathbf{n = 8 4})$ & Central (Group B) $(\mathbf{n}=\mathbf{1 1 6})$ & \\
\hline Severe & $36(42.86 \%)$ & $25(21.55 \%)$ & 0.05 (significant) \\
\hline
\end{tabular}

Chi-square test, $\mathrm{p}$ value: 0.05 , Odds ratio: $4.398, \mathrm{CI}: 1.174-16.46$.

Table 4: Maternal outcome according to placental location.

\begin{tabular}{|llll|}
\hline \multirow{2}{*}{ Maternal Complications } & $\begin{array}{l}\text { Placental location } \\
\text { Lateral }(\mathbf{n}=\mathbf{8 4})\end{array}$ & Central $(\mathbf{n = 1 1 6})$ & Statistical significance (p value) \\
\hline Eclampsia & $7(8.3 \%)$ & $1(0.86 \%)$ & 0.008 (VHS) \\
\hline Abruptio & $5(6 \%)$ & $2(1.7 \%)$ & 0.103 (non-significant \\
\hline HELLP syndrome & $2(2.4 \%)$ & $0(0.0 \%)$ & NA \\
\hline DIC & $0(0.0 \%)$ & $0(0.0 \%)$ & NA \\
\hline IUGR & $13(15.48 \%)$ & $6(5.17 \%)$ & 0.014 (HS) \\
\hline Renal failure & $4(4.8 \%)$ & $0(0.0 \%)$ & NA \\
\hline Preterm labour & $17(20.24 \%)$ & $18(15.5 \%)$ & 0.385 (non-significant) \\
\hline Sepsis & $2(2.4 \%)$ & $1(0.9 \%)$ & 0.394 (non-significant) \\
\hline Transfer to RICU/ICU & $3(3.6 \%)$ & $0(0.0 \%)$ & NA \\
\hline Mortality & $0(0.0 \%)$ & $0(0.0 \%)$ & NA \\
\hline
\end{tabular}

VHS: Very highly significant, HS: Highly significant.

The maternal complications were found to be more in women with lateral placenta compared to women with central placenta as depicted in Table 4. In women with lateral placenta, $8.3 \%$ women developed eclampsia while 
$0.086 \%$ women with central placenta developed eclampsia. IUGR was seen in $15.4 \%$ women with lateral placenta and only $5.17 \%$ women with central placenta. Thus, IUGR and eclampsia were statistically significant in women with lateral placenta ( $\mathrm{p}$ value $0.014,0.008$ respectively).
Among women with lateral placenta, 57.14\% had spontaneous onset of labour and $42.86 \%$ delivered after being induced whereas among women with central placenta, $66.4 \%$ had spontaneous onset of labour and $33.6 \%$ were induced ( $\mathrm{p}$ value 0.183 ). Maximum number of women in both the groups delivered vaginally.

Table 5: Perinatal complications according to placental location.

\begin{tabular}{|llll|}
\hline Neonatal complications & $\begin{array}{l}\text { Placental location } \\
\text { Lateral (Group A) } \\
(\mathbf{n = 8 4 )}\end{array}$ & $\begin{array}{l}\text { Central (Group B) } \\
(\mathbf{n = 1 1 6})\end{array}$ & $\begin{array}{l}\text { Statistical significance (p } \\
\text { value) }\end{array}$ \\
\hline LBW (birth weight $<2.5 \mathrm{~kg})$ & $38(45.2 \%)$ & $31(26.7 \%)$ & $0.006(\mathrm{VHS})$ \\
\hline Prematurity & $16(19.05 \%)$ & $17(14.7 \%)$ & $0.406(\mathrm{NS})$ \\
\hline Neonatal sepsis & $5(5.95 \%)$ & $6(5.17 \%)$ & $0.810(\mathrm{NS})$ \\
\hline NICU admission & $24(28.6 \%)$ & $17(14.7 \%)$ & $0.016(\mathrm{HS})$ \\
\hline Perinatal mortality & $5(5.95 \%)$ & $4(3.45 \%)$ & $0.401(\mathrm{NS})$ \\
\hline Still Birth & $3(3.57 \%)$ & $2(1.72 \%)$ & $0.406(\mathrm{NS})$ \\
\hline Neonatal death & $5(5.95 \%)$ & $4(3.45 \%)$ & $0.400(\mathrm{NS})$ \\
\hline Apgar at 1 min $<7$ & $34(40.5 \%)$ & $32(27.6 \%)$ & - \\
\hline Apgar at 5 min & $8(9.5 \%)$ & $3(2.6 \%)$ & - \\
\hline
\end{tabular}

HS: Highly significant, NS: Not significant, VHS: very highly significant.

Table 5 depicts perinatal outcome in women according to placental location. All perinatal complications like low birth weight, prematurity, neonatal sepsis, still birth, neonatal death, birth asphyxia and NICU admissions were higher in neonates belonged to Group A compared to neonates belonged to Group B but statistically significant difference was found for low birth weight, birth asphyxia and NICU admission. Mean hospital stay in women with lateral placenta was $6.15 \pm 5.26$ and $3.86 \pm 3.75$ in women with central placenta ( $p$ value $0.001)$.

\section{DISCUSSION}

Preeclampsia is a complex clinical syndrome which involves multiple organ systems and remains the principle cause of maternal and perinatal morbidity and mortality. The search for an ideal and reliable predictive measure remain challenging. Among the various predictors for preeclampsia, the placental location by ultrasound at 18-24 weeks is very cost effective, noninvasive and has a good predictive value. When the placenta is laterally located, the uterine artery close to the placenta has lower resistance than the opposite from it and the uteroplacental blood flow needs are to be met primarily by one of the uterine arteries with some contribution by the other uterine artery via collateral circulation. The degree of collateral circulation may not be same in all patients, and deficient circulation may facilitate the development of preeclampsia, IUGR or both. $^{12}$

In the present study, authors observed that lateral placentation is less common than central placentation.
Out of total 200 women, $84(42 \%)$ had lateral placenta and $116(58 \%)$ had central placenta. Similar results were found by Gosh et al, Muralidhar et al, Bhalerao et al, Maggan et al. ${ }^{13-16}$

In the present study, $65.5 \%$ women with lateral placenta and $24.1 \%$ women with central placenta developed preeclampsia. This difference was statistically significant ( $\mathrm{p}$ value $<0.001$ ). This study is consistent with the study conducted by Kakkar et al, who concluded that $66.6 \%$ women with lateral placenta and $36.3 \%$ with central placenta developed preeclampsia. ${ }^{17}$ Similar results were depicted from study concluded by Sandhya et al, Ambastha et al. ${ }^{18,19}$

It was demonstrated in our study that out of 83 women who developed preeclampsia, 22 women developed severe preeclampsia. Out of those 22 women, 19 $(86.36 \%)$ had lateral placenta and three (13.64\%) had central placenta. These results correlate with the study conducted by Chandra et al, Kangjam et al. ${ }^{20,21}$ In the study conducted by Kangjam et al, it was observed that out of total women who developed severe preeclampsia, $88.9 \%$ had lateral placenta and $11.1 \%$ had central placenta. $^{21}$

Urine albumin is significantly associated with placental location ( $p$ value $<0.05$ ) in the present study. This is in accordance with the study conducted by Bhattacharjee AK et al and Chandra et al, they concluded that majority of the cases of severe preeclampsia who were having proteinuria $(>1+)$ had lateral location of placenta. ${ }^{20,22}$ 
It was found that maximum number of women in both the groups delivered at $>36$ weeks. No significant difference was seen in period of gestation at delivery in both the groups. This is in agreement to the study conducted by Salamo et al, who also concluded that there is no association between placental location and gestational age at delivery. ${ }^{23}$

In the present study it was demonstrated that $79.8 \%$ women in Group A and 79.3\% women in Group B delivered vaginally. In Group A, 20.2\% women and in Group B $20.7 \%$ women underwent LSCS. This difference in mode of delivery between women with lateral and central placenta was not found to be statistically significant. Similar results were observed by Bhalerao et al, who also concluded that there was no association between lateral/central placental location with mode of delivery ( $\mathrm{p}$ value 0.928 ). ${ }^{15}$

Gosh et al, found in their study that maternal complications like eclampsia, IUGR babies were statistically more in women with lateral placenta compared to women with central placenta. ${ }^{13}$ Similarly, Ambastha et al and Kore et al also demonstrated that IUGR babies were found to be more in women with lateral placenta. In the present study, it was observed that all the complications (preterm labour, eclampsia, HELLP syndrome, IUGR babies, transfer to RICU/ ICU were higher in women with lateral placenta but only eclampsia and IUGR were statistically significant ( $\mathrm{p}$ value 0.008 and 0.014 respectively). ${ }^{19,24}$ In women with lateral placenta, $4.8 \%$ developed renal failure and $3.6 \%$ women transferred to RICU/ICU. In contrast to this, no women with central placenta developed renal failure and transferred to RICU/ICU.

It was observed that Apgar score $<7$ at 1 and 5 minutes was present in more number of neonates who belonged to women with lateral placenta compared to women with central placenta. This difference in apgar score was found to be statistically significant ( $p$ value 0.030 and 0.033 respectively). Similar to this study, Maggan et al had comparable results who observed that there as significant decrease in Apgar score at both 1 and 5 minutes in neonates belonged to women with lateral placenta. ${ }^{16}$

In present study, low birth weight babies $(<2.5 \mathrm{~kg})$ were significantly more in women with lateral placenta compared to women with central placenta. There was significant reduction in mean birth weight in babies belonged to Group A (i.e. $2.42 \pm 0.62 \mathrm{~kg}$ ) compared to babies belonged to group B (i.e. $2.67 \pm 0.57 \mathrm{~kg}$ ). Similarly, in accordance to our study, Bhalerao et al observed that babies with birth weight $<2.5 \mathrm{~kg}$ were higher in women with lateral placenta (i.e. $65.38 \%$ ) compared to women with central placenta $(47.36 \%) .{ }^{15}$

NICU admissions and prematurity were higher in babies belonged to women with lateral placenta compared to those with central placenta in our study. Seckin et al, also elucidated that lateral placental location was significantly associated with need for neonatal intensive care unit, fetal growth restriction, preterm births and low Apgar scores. ${ }^{25}$

From present study it was observed that mean hospital stay in women with lateral placenta was $6.15 \pm 5.26$ days and in women with central placenta was $3.86 \pm 3.75$ days and this difference was found to be statistically significant.

\section{CONCLUSION}

It is concluded that laterally located placenta on ultrasound done at $18-24$ weeks is associated with five times increased risk of development of preeclampsia. The maternal complications like IUGR, eclampsia and perinatal complications like low birth weight, NICU admissions were significantly higher in women with lateral placenta compared to women with central placenta. Ultrasonography is a simple, non-invasive, cost effective predictive screening test for the development of preeclampsia. We recommend that if lateral placenta is detected on ultrasound, one should be vigilant for careful obstetric management to achieve more favourable outcome and to prevent some of the dreadful complications and decreases the maternal and perinatal morbidity and mortality.

Funding: No funding sources

Conflict of interest: None declared

Ethical approval: The study was approved by the Institutional Ethics Committee

\section{REFERENCES}

1. Tranquilli AL, Dekker G, Magee L, Roberts J, Sibai BM, Steyn W, et al. The classification, diagnosis and management of the hypertensive disorders of pregnancy: a revised statement from the ISSHP. Pregnancy Hypertens. 2014;4:97-104.

2. Studd J, Lin Tan S, Chervenak FA, editors. Current Progress in Obstetrics and Gynaecology. $4^{\text {th }}$ ed. New York: Tree Life; 2017:108-154.

3. Cunningham FG, Veno KJ, Bloom SL. Pregnancy hypertension. In: William Obstetrics. 23rded. New York: McGraw-Hill Medical; 2010:706-756.

4. Lain KY, Roberts JM. Contemporary concepts of the pathogenesis and management of preeclampsia. $\mathrm{J}$ Am Med Assoc. 2002;287:3183-6.

5. Shivamurthy HM, Sharada KS, Giridhar SA, Jyotsna RH, Asaranna D. Placental laterality as a predictor of preeclampsia: an ultrasonic prospective study. J Pub Health Med Res. 2014;2:38-40.

6. Rivers EP. The clinical practice of emergency medicine. In: Preeclampsia, eclampsia, and other hypertensive disorders of pregnancy. $2^{\text {nd }}$ edition. Lippincott Williams and Wilkins; 1996:315-321.

7. Kuklina EV, Ayala C, Callaghan WM. Hypertensive disorders and severe obstetric morbidity in the United States. Obstet Gynaecol. 2009;113:1299-306. 
8. Kaku R, Shivaraju P, Vimala KR, Lingegowda K. Lateral location of placenta on ultrasound as a predictive test for pre-eclampsia. Int $\mathrm{J}$ Reprod Contracept Obstet Gynaecol. 2017;6:930-3.

9. Grill S, Rusterholz C, Zanetti- Dallenbach R, Tercanli S, Holzgreve W, Haahn S, et al. Potential markers of preeclampsia: a review. Reprod Biol Endocrinol. 2009;7:70.

10. Muralidhar VP, Jyothi P. Placental laterality by ultrasound: a simple yet reliable predictor test for pre-eclampsia. Indian J Obstet Gynaecol. 2005;55:431-3.

11. Kannamani A, Narasimhan D. A study on analysis of validity of lateral placental location in prediction of preeclampsia. J Evol Med Dent Sci. 2017;6:1401-3.

12. Gupta A, Kakkar M. Placental laterality as a predictor for development of preeclampsia. J Obstet Gynaecol India. 2003;63:22-5.

13. Gosh M, Gosh A, Sengupta P. A study to assess placental location by ultrasonography and evaluation of its relationship with development of preeclampsia and eclampsia. Int J Biomed Res. 2017;8:668-71.

14. Muralidhar VP, Jyothi P. Placental laterality by ultrasound: a simple yet reliable predictor test for pre-eclampsia. Indian $\mathbf{J}$ Obstet Gynaecol. 2005;55:431-3.

15. Bhalerao AV, Kulkarni S, Somalwar S. Lateral placentation by ultrasound: a simple predictor of preeclampsia. J South Asian Feder Obst Gynae. 2013;5:68-71.

16. Magann EF, Doherty DA, Turner K, Lanneau GS, Morrison JC, Newnham JP. Second trimester placental location as a predictor of an adverse pregnancy outcome. J Perinatol. 2007;27:9-14.

17. Kakkar T, Singh V, Ranzdan R, Sanjeev KD, Gupta A, Kakkar M. Placental laterality as a predictor for development of preeclampsia. J Obstet Gynaecol. 2012;63:22-5.
18. Sandhya K, Madhavi GB, Chandramathi M. Placental laterality as a predictor of pre-eclampsia. Am J Phytomed Clin Therapeut. 2015;3:231-6.

19. Ambastha V, Sreelatha S, Devi A, Kallesh S, Sumaiah, Kavitha LB, et al. Study of association of lateral implantation of placenta with development of preeclampsia and its outcome. The New Indian J Obstet Gynaecol. 2018;5:33-7.

20. Chandra K, Maheshwari S. Placental laterality: as a predictor for the development of pre-eclampsia. J Dent Med Sci. 2016;15:6-10.

21. Aggarwal P, Kangjam P, Terhase N. Study on relation between placental laterality in second trimester ultrasound and development of preeclampsia at term. J Evol Med Dent Sci. 2015;4:16926-8.

22. Bhattacharjee AK, Majumdar MK, Basumatary L. Placental laterality by ultrasound and its correlation to development of preeclampsia. Sch J App Med Sci. 2017;5:4197-200.

23. Salama-Bello R, Jose R, Howard S, Song J, Schenone M. Placental location and the development of hypertensive disorders of pregnancy. Am In Ultra Med. 2018;38:1-5.

24. Kore SJ, Khot R, Supe P, Kanavia D, Thunga C, Nandanwar Y. Prediction of pre-eclampsia: Role of placental laterality by ultrasonography. Int J Reprod Contracept Obstet Gynaecol. 2016;5:1433-7.

25. Seckin KD, Cakmak B, Karsali MF, Yeral MI, Gultekin B, Danisman N. Is lateral localization of placenta a risk factor for adverse perinatal outcomes. Obs Gynaecol. 2015;35:6696-8.

Cite this article as: Gupta A, Bansal P, Sen J, Singhal SR. Correlation of lateral placental location with development of preeclampsia. Int J Reprod Contracept Obstet Gynecol 2020;9:1017-22. 